Est Ag 54 (2018) 27-49

\title{
El ayuno en la Didajé $e^{1}$
}

DAVID Álvarez Cineira

RESUMEN: La praxis del ayuno, ampliamente conocida en el mundo judío y asumida por algunas comunidades cristianas, se empleó en el cristianismo naciente con diferentes funciones, tal y como testimonia la Didajé: como signo de identidad grupal $(8,1)$, expresión de amor $(1,3)$ y elemento preparatorio al rito iniciático del bautismo (7,4). Este constituye el testimonio más antiguo del ayuno prebautismal, transmitiendo una praxis existente en su comunidad, sin necesidad de justificarla. Probablemente se entendía como un elemento liminal del rito bautismal y, como acto colectivo, denotaba la solidaridad espiritual de la comunidad con el candidato.

Palabras clave: Ayuno, Didajé, rito prebautismal, ritos de pasaje.

Abstract: The praxis of fasting, widespread in the Jewish world and adopted by some Christian communities, was used in the nascent Christianity with different functions, as the Didache testifies: as group identity sign $(8,1)$, as expression of love $(1,3)$ and as preparatory element for the baptism $(7,4)$. This is the oldest testimony of the prebaptismal fasting, transmitting an existing praxis in its community, without needing to justify it. Probably it was understood as a liminal element of ritual of the baptism and, as a collective act, denoted the spiritual solidarity of the community with the candidate.

Keywords: Fasting, Didache, prebaptismal rite, rites of passage.

\footnotetext{
${ }^{1}$ Este pequeño artículo pretende ser expresión de mi gratitud hacia D. Luis Resines por su constante colaboración con la Revista y por su labor docente en el centro durante muchos años: en un primer momento, como mi profesor y, posteriormente, como compañero en el claustro de profesores.
} 
La abstención voluntaria, parcial o total, de alimentos y, a veces, de bebida durante un período de tiempo, como observancia religiosa o como expresión de dolor comunitario es un hecho constatado en diversas culturas a lo largo de la historia. En las religiones greco-romanas, sin embargo, los dioses esperaban la adoración y el sacrificio, pero mostraron poco interés por regular la vida cotidiana de las personas y, menos, la alimentación. Médicos y filósofos propusieron pautas para salvaguardar la salud del cuerpo, pero estas reglas de conducta eran productos del pensamiento y la consideración humana, no mandato divino ${ }^{2}$. Sin embargo, la comida y el ayuno desempeñaron un papel importante en la configuración de la identidad del judaísmo, tal y como se expresa en fuentes judías y greco-romanas. "Ayunar como un judío" llegó a ser proverbial en el mundo romano (Suetón, Aug. 76) y constituyó una praxis extendida durante la época del Segundo Templo y en los períodos rabínicos. En realidad, solo existía un ayuno exigido por la ley mosaica, el día de la expiación (Lv 16,1-34; Núm 29,7-11)33, no obstante diferentes grupos judíos instituyeron otros días de privación.

Probablemente Jesús también ayunó de forma ocasional, en concreto el día de la expiación, pues un comportamiento antinómico habría dejado rastro en nuestras fuentes y no hubiera sido fácil recordarlo ayunando ${ }^{4} \mathrm{y}$ ofreciendo instrucciones al respecto (Mt 6,16-18) ${ }^{5}$. Mc 2,18-22 (= Mt 9,9-13; Lc 5,27-32) conserva una tradición en la que preguntan a Jesús por qué sus discípulos, a diferencia de los fariseos y los discípulos de Juan el Bautista, no ayunan. El interpelado responde con la parábola de los invitados a la boda, según la cual mientras el novio esté presente, no cabe la posibilidad

\footnotetext{
${ }^{2}$ R. Arbesmann, "Fasten”, en: Theodor Klauser (ed.), Reallexikon für Antike und Christentum. Sachwörterbuch zur Auseinandersetzung des Christentums mit der antiken Welt, Band VII, Anton Hiersemann, Stuttgart 1969, 447-500, esp. 447-451; Peter Gerlitz, „Fasten/Fasttage I“, Theologische Realenzyklopädie, Band 11, Walter de Gruyter, Berlin - New York 1983, 42-

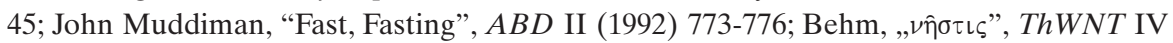
925-935.

${ }^{3}$ Daniel Stökl Ben Ezra, The Impact of Yom Kippur on Early Christianity. The Day of Atonement from Second Temple Judaism to the Fifth Century (WUNT 163), Mohr Siebeck, Tübingen 2003.

${ }^{4}$ Los relatos de la tentación de Jesús en los sinópticos tienen carácter legendario, el material en Mt 6,6-18 se encuentra solo en Mateo.

${ }^{5}$ Jesús ofrece instrucciones detalladas (y sin paralelo) acerca del ayuno como parte de una pequeña enseñanza cúltica sobre la limosna, la oración y el ayuno. Presumiblemente, el tema no es el ayuno público, sino el ayuno voluntario privado (como en Neh 1,4; Dan 9,3; Lc $2,37 ; 18,12)$.
} 
de ayunar ${ }^{6}$. Esta secuencia de preguntas y respuestas sugiere que el comportamiento de Jesús fue visiblemente diferente al de otros judíos. El pasaje se podría explicar adecuadamente si Jesús, en contraste con los seguidores del Bautista y algunos fariseos, no participaba en los ayunos voluntarios que algunos judíos piadosos observaban semanalmente (cf. Lc 18,12). Además, en Q 7,33-34, los oponentes critican a Jesús de comilón y borracho, acusación que difícilmente concuerda con una vida ascética.

Al margen de los evangelios sinópticos y Hechos de los Apóstoles $(13,2-3 ; 14,23 ; 27,9)$, el ayuno juega un papel irrelevante en el resto de los escritos neotestamentarios. Los textos que se refieren a él, no justifican ni explican su propósito. Parece ser un acto de adoración, pero no afirman que colabore a que la oración sea más efectiva (cf. Jer 14,11-12; Neh 1,4), fomente experiencias visionarias (cf. 1Sam 28,20; Dan 10,3; 4 Esd 5,20; 2 Bar 20,5-6), facilite la expulsión de los demonios (Mc 9,29) o transforme a las personas como ángeles. No sorprende, pues, que grupos cristianos posteriores abandonaran el ayuno ${ }^{7}$.

No obstante, otros cristianos ayunaron y crearon la historia de Jesús ayunando en el desierto, el material de Mt 6,16-18 y la afirmación del ayuno en Mc 2,20. Es llamativo que solo tres o cuatro décadas tras la muerte de Jesús, algunos grupos cristianos judíos representados en la Didajé, muy vinculados al judaísmo y a una zona geográfica muy concreta, prescriban expresamente el ayuno con unos objetivos novedosos y otorgándole un significado desconocido hasta ese momento en el resto de las comunidades cristianas. Ello denota la creatividad de las comunidades desde muy antiguo y la capacidad de adaptación de elementos rituales existentes para nuevos fines. El presente artículo estará dedicado a determinar las funciones del ayuno en las comunidades de la Didajé, para lo cual comenzaremos abordando su datación, lo que nos permitirá constatar la antigüedad de las nuevas funciones otorgadas a este ritual.

${ }^{6}$ Mc 2,20 afirma que "vendrán días cuando el novio sea arrebatado" y entonces sus amigos ayunarán. Generalmente, se considera un apéndice pospascual para justificar el ayuno cristiano.

${ }^{7}$ EvT 14 es la antítesis de Mt 6,1-18: "Jesús les dijo: Si ayunáis os engendraréis pecados y si rezáis seréis condenados y si dais limosna haréis mal a vuestros espíritus". cf. Apocalipsis de Elías (copto) 1,13-22; "El ayuno no tiene validez, ni Dios lo instituyó" (3,3-4), según el texto de Albert Pietersma - Susan Turner Comstock - Harold W. Attridge, The Apocalypse of Elijah based on P. Chester Beatty 2018, Society of Biblical Literature, Scholar Press, Chico Ca. 1981, 25. 


\section{Datación, localización y composición de la Didajé}

La fecha y procedencia de la Didajé han sido temas controvertidos desde la primera edición de su texto realizada por Filoteos Bryennios en 1883. Tal y como he recopilado en otra ocasión ${ }^{8}$, el arco de fechas sugeridas para su composición final abarca desde los años 50 d.C. hasta la primera mitad del siglo II. La dificultad radica en que no existen pruebas claras y el problema se complica por el carácter compilatorio de sus fuentes o tradiciones. Kurt Niederwimmer resumió sus investigaciones al sugerir la fecha de finales del siglo I d.C. para las fuentes, mientras que la redacción final, obra del didajista, vendría situada entre los años 110 y 120 d.C. ${ }^{9}$. Esta propuesta constituyó el consenso de la investigación hasta los años 1990. Estudios posteriores, sin embargo, basados en las evidencias internas y en el contenido del documento, han sugerido una datación anterior. Thomas O'Loughlin habla de un amplio consenso actual a favor de una datación en el s. I d.C. Él mismo señala una fecha temprana, hacia el año 50 d.C.: "Con toda probabilidad, una versión de la Didajé fue confiada a la memoria de grupos de seguidores de Jesús a mediados del siglo primero - y lo que ahora tenemos refleja una etapa muy primitiva de la vida e influencia de ese texto" ${ }^{10}$. Las hipótesis de una dependencia literaria de la Didajé respecto al

${ }^{8}$ „Die Didache im Formationsprozess des frühen Christentums“, en: Giancarlo Collet - Dorothea Sattler (Hrgs.), In Konflikten leben: Mit Zorn und Zärtlichkeit an der Seite der Armen. Ein Beitrag zur ökumenischen Dekade zur Überwindung von Gewalt, Lit Verlag, Münster 2012,107-147, aquí 113-117. Para una visión general de la investigación sobre la Didajé en las últimas década cf. Shawn J. Wilhite, "Thirty-Five Years Later: A Summary of Didache Scholarship Since 1983”, CBR 17 (2019) 266-305.

${ }^{9}$ Kurt Niederwimmer, Die Didache (KAV 1), 2. ergänzte Auflage, Vandenhoeck \& Ruprecht, Göttingen 1993, 79: „Die Ansetzung um 110 oder 120 n. Chr. bleibt hypothetisch, doch gibt es bisher keine zwingenden Gründe, diese Hypothese fallen zu lassen“"

${ }^{10}$ Thomas O'Loughlin, The Didache: A Window on the Earliest Christians, SPCK, London 2010,26, considera el texto como "a window on the first and second generation of Christians, who were close to the patterns of Jewish faith, seeking to understand the new way of Jesus" (p. 27). Véase el resumen de su libro: "This book has been an exploration of one short text from the first generations of Christians" (p. 160). Aaron Milavec, The Didache. Faith, Hope \& Life of the Earliest Christian Communities, 50-70 C.E., Newman Press, New York 2003, ha hecho de la datación temprana parte del título de su voluminoso libro y considera la Didajé una catequesis oral. Otros autores que postulan una datación temprana del escrito: Jonathan A. Draper, "The Didache in Modern Research: An Overview”, en: Jonathan A. Draper (ed.), The Didache in Mother Research (AGAJU 37), E.J. Brill, Leiden - New York - Köln 1996, 1- 
evangelio de Mt no se han impuesto, pues los elementos comunes pudieran remontar a tradiciones compartidas ${ }^{11}$. Además, varios estudiosos han defendido una relación más compleja entre Mateo y la Didajé: un "texto de crecimiento o literatura progresiva", es decir, un texto que ha tenido una larga historia de redacción ${ }^{12}$ dentro de una comunidad viva y en desarrollo, a lo que se añade la influencia continua de la oralidad en la producción y transmisión del texto ${ }^{13}$. Según las nuevas tendencias en la investigación de este documento, nos encontramos ante el escrito cristiano no canónico más antiguo, anterior incluso a muchos libros del NT, probablemente de los años 70 d.C.

Controvertida, igualmente, ha sido la localización de su composición o la ubicación de las comunidades destinatarias del documento. El texto no ofrece ninguna indicación topográfica. Los únicos datos que aporta el opús-

42; Michelle Slee, The Church in Antioch in the First Century CE: Communion and Conflict (JSNTSup 244), Sheffield Academic Press, London 2003, 54-76: antes del ev. Mt "possibly as early as the mid-first century CE" (p. 76); Alan J. Ph. Garrow, The Gospel of Matthew's Dependence on the Didache (JSNTSup 254), T\&T Clark, London 2004; Jonathan Schwiebert, Knowledge and the Coming Kingdom: The Didache's Meal Ritual and its Place in Early Christianity (LNTS 373), T\&T Clark, London 2008; Owen F. Cummings, "The Didache and the Eucharist," Immanuel 118 (2012) 120-31. Defensores de una datación más tardía, alrededor de los años 110-20 d.C. incluyen, aunque dudoso, Kurt Niederwimmer, Didache 79; Huub van de Sandt - David Flusser, The Didache: Its Jewish Sources and Its Place in Early Judaism and Christianity (CRINT 3.5), Van Gorcum - Fortress, Assen - Minneapolis 2002, 48, "turn of the first century"; Clayton N. Jefford, "Didache," EDB,345a-46a, sugiere un arco más amplio de fechas (70-150 d.C.), pero prefiere una datación a principios del siglo II d.C.

${ }^{11}$ E. Bruce Brooks, "Before and after Matthew", en: Clayton N. Jefford (eds.), The Didache. A Missing Piece of the Puzzle in Early Christianity, SBL Press, Atlanta 2015, 247-286, defiende que la Didajé es un texto de crecimiento, que tuvo contacto con Mateo solo al final de su período de formación, mientras que su núcleo se entiende mejor si se relaciona con el período anterior a Mateo y Lucas: el tiempo de Marcos, al que denominará "cristianismo alfa".

${ }^{12}$ Cf. D.A. Cinera, "Die Didache"111-113. Recientemente, Pardee y Jefford han intentado reconstruir el desarrollo histórico de la comunidad de la Didajé a partir de sus estratos redaccionales. Proponen varias etapas de composición del documento, con nuevos materiales incluidos en cada etapa para responder a los desafíos de la comunidad. Estos desafíos incluyen la tensión entre creyentes judíos y gentiles y la necesidad de regular los rituales, así como el sistema organizativo de las comunidades cristianas. Nancy Pardee, The Genre and Development of the Didache: A Text-linguistic Analysis (WUNT II 339), Mohr Siebeck, Tübingen 2012, 141-187; Clayton N. Jefford, Teaching of the Twelve Apostles: Didache, Polebridge, Santa Rosa, CA 2013.

${ }^{13}$ Cf. Jonathan A. Draper, "Missing Pieces in the Puzzle or Wild Goose Chase? A Retrospect and Prospect", en: Clayton N. Jefford (eds.), The Didache. A Missing Piece, 529-543. 
culo son su lenguaje griego y el hecho de que parte de la obra vaya dirigida a cristianos provenientes del mundo gentil. Por otro lado, el contenido del documento, así como el empleo de la sección judía de los Dos Caminos (Did 1-6) nos indican que se trataba de una comunidad orientada al judaísmo, a saber, algún tipo de comunidad judeocristiana. Considerando estos dos componentes, judeocristianismo y destinatarios gentiles, se han propuesto dos lugares como contexto originario de la Didajé: Egipto o Siria-Palestina. La capital de la provincia de Siria, Antioquía, es para muchos eruditos una sugerencia plausible, porque contaba con numerosa población judía y, evidentemente, dicha ciudad jugó un papel relevante en la iglesia desde los primeros tiempos apostólicos. Sin duda, la hipótesis de Antioquía ha ganado cada vez más adeptos ${ }^{14}$, en parte también por la relación de la $D i$ dajé con los textos de Mt y Santiago ${ }^{15}$.

Esta incertidumbre referente a la fecha y procedencia de sus fuentes o redacción final del opúsculo es relevante para investigar la identidad de la comunidad de la Didajé y comprender el desarrollo de la relación de los primeros creyentes de Jesús con su propio origen judío y con el creciente número de conversos gentiles. En cuanto al mapa ideológico y social del escrito, la mayoría de los eruditos considera que varias secciones de la $\mathrm{Di}$ dajé provienen de un contexto judío y muestran un elevado grado de continuidad con el judaísmo.

David Flusser y Huub van de Sandt han realizado hasta el momento el estudio más extenso sobre las raíces judías de la Didajé. Tras rastrear las

\footnotetext{
${ }^{14}$ Nancy Pardee, "Visualizing the Christian Community at Antioch. The Window of the Didache", Forum third series 3,1 (2014) 69-90. Clayton N. Jefford, "Locating the Didache", Forum third series 3,1 (2014) 39-68, hace un buen resumen del status questionis referente a la localización (p. 62s.) y datación de la Didajé hasta la obra de Nancy Pardee (pp. 39-59). Jefford argumenta además que Ignacio de Antioquía conoció alguna forma anterior de la $D i$ dajé, aunque no la citó. Cf. Clayton N. Jefford, "Did Ignatius of Antioch Know the Didache?", en: Clayton N. Jefford (ed.), The Didache in Context: Essays on Its Text, History and Transmission (NovTSup 77), Brill, Leiden 1995, 330-51 y Clayton N. Jefford, "The Milieu of Matthew, the Didache, and Ignatius of Antioch: Agreements and Differences", en: Huub van de Sandt (ed.), Matthew and the Didache: Two Documents from the Same Jewish-Christian Milieu?, Royal Van Gorcum - Fortress, Assen - Minneapolis 2005, 35-47.

${ }^{15}$ Véanse los artículos recogidos en Huub van de Sandt - Jürgen K. Zangenberg (eds.), Matthew, James, and Didache. Three related documents in their Jewish and Christian Setting, Society of Biblical Literature, Atlanta 2008; Gunnar Garleff, Urchristliche Identität in Matthäusevangelium, Didache und Jakobusbrief (Beiträge zum Verstehen der Bibel 9), Lit, Münster 2004.
} 
afinidades de la sección de los Dos Caminos en Did 1-6 con varias tradiciones judías, afirman que la Didajé es una adaptación de las tradiciones judías a las necesidades de la comunidad cristiana ${ }^{16}$. Este documento se compuso en un momento en que la iglesia local comenzaba a definirse como distinta de sus raíces judías. En tal período de transición, se formaron varios grupos dentro de los seguidores de Jesús, por lo que una de las principales preocupaciones del didajista fue superar la tensión entre estos grupos, así como salvaguardar la unidad e identidad de su comunidad frente a las amenazas internas y del mundo exterior, con el fin de evitar una división aparentemente irreversible dentro de la comunidad. Sin embargo, ven dos estrategias opuestas en la Didajé para lograr dicho objetivo. La posición dominante de la sección los Dos Caminos revela una comunidad que se define frente al mundo gentil apelando a sus raíces judías ${ }^{17}$. Por otro lado, la Didajé (7-10) trata de reemplazar la liturgia y las prácticas rituales judías con un culto transformado que refleja un mayor interés en los conversos gentiles y una separación de la comunidad de la Didajé frente a los judíos ${ }^{18}$. El texto muestra incluso una actitud de animosidad hacia ciertas orientaciones del judaísmo, al denominarlos "hipócritas", siendo conscientes de la amplia gama y la diversidad de la cultura judía del siglo primero. No existía una expresión religiosa monolítica judía en los primeros dos siglos d.C., sino más bien un espacio público disputado. Así, el judaísmo rabínico representa una orientación, entre otras muchas, dentro de una tradición en evolución que lucha por la hegemonía después del colapso del templo de Judea. Por su parte, la Didajé constituye otra corriente del judaísmo, que

${ }^{16}$ Huub van de Sandt - David Flusser, The Didache. Cf. Marcello del Verme, Didache 4.

${ }^{17}$ Huub van de Sandt - David Flusser, Didache 58. Van de Sandt señala que tanto en la Didajé como en Mateo, las obligaciones éticas para los miembros de sus respectivas comunidades se definen en términos notablemente judíos de la observancia de la Torá. Cf. Huub van de Sandt, "Essentials of Ethics in Matthew and the Didache: A Comparison at a Conceptual and Practical Level", en: Jan Willem van Henten - Joseph Verheyden (eds.), Early Christian Ethics in Interaction with Jewish and Greco-Roman Contexts (STAR 17) Brill, Leiden - Boston 2013, 244.

${ }^{18}$ Huub van de Sandt analiza la función de los rituales como reguladores a la hora de redefinir la identidad social de la comunidad como distinta de la identidad judía, cf. Huub van de Sandt, "The Didache Redefining Its Jewish Identity in View of Gentiles Joining the Community”, en: Alberdina Houtman - Albert de Jong - Magda Misset-van de Weg (eds.), Empsychoi Logoi-Religious Innovations in Antiquity. Studies in Honour of Pieter Willem van der Horst, Brill, Leiden 2008, 245-65. 
basa sus afirmaciones en la aceptación de Jesús como descendiente de David y Mesías. Sus rituales y cristología difieren de otros grupos de seguidores de Jesús, pero existe cierta sintonía con los patrones encontrados en Mateo, Santiago y el Apocalipsis.

Se discute el grado de separación o inserción dentro del judaísmo, existiendo grosso modo dos posturas: a) quienes postulan una separación más o menos nítida entre el judaísmo y el cristianismo representado por la comunidad portadora de la Didajé, y b) quienes consideran que la obra expresa una discusión ad intra dentro del judaísmo, donde la comunidad(es) de la Didajé constituía un grupo más del mundo judío. No se habría llegado a una ruptura con el judaísmo, pues nos encontraríamos en una época muy temprana. Personalmente, considero que la ruptura con el judaísmo no se había consumado ${ }^{19}$. Pero centrémonos en el ayuno.

\section{El ayuno}

Did 7-10 contiene instrucciones sobre los rituales del bautismo (Did 7) y la eucaristía (Did 9-10), el ayuno y las oraciones (Did 8), sin proporcionar una enseñanza integral. Más bien, son selectivas y, en ocasiones, solo se refieren a cuestiones secundarias. Dicha naturaleza selectiva sugiere que estas directrices intentaban responder a problemas reales de la comunidad. Los textos, especialmente los que dan instrucciones para las actividades grupales, surgen dentro de comunidades existentes previas a sus productos literarios. Además, las normativas rituales no solo regulan las prácticas en sí mismas, sino que pueden afectar a la visión del mundo, a la identidad y a las actitudes de una comunidad. En particular, se observa que los elementos cristológicos son más prominentes en Did 7-10 que en la sección anterior de los Dos Caminos. Esto sugiere que la sección ritual podría revelarnos rasgos de la identidad y autocomprensión de las comunidades destinatarias de este documento frente a otros grupos. Aquí nos limitaremos al ritual del ayuno, que aparece en tres ocasiones en este opúsculo. En Did 8,1 se emplea como signo de identidad grupal frente a los hipócritas. Como este tema ya lo he abordado en otro estudio ${ }^{20}$, me centraré aquí en los otros

\footnotetext{
${ }^{19}$ D.A. Cineira, "Die Didache" 143-147.

20 "El ayuno, signo de identidad".
} 
dos pasajes, el ayuno como forma de amor y el ayuno en el rito iniciático del bautismo.

\subsection{El ayuno como expresión de amor}

La primera mención del ayuno en la Didajé se encuentra al inicio del documento donde aparece un dicho que forma parte de la enseñanza conocida como los Dos Caminos y, en concreto, pertenece a la sección denominada comúnmente sectio evangelica $(1,3 \mathrm{~b}-2,1)$, en la que subyacen logia de la tradición de Jesús (vv. 1,3.4b-5a.5d), sin que podamos afirmar con certeza su procedencia. El didajista habría añadido esta unidad con el objeto de cristianizar el tratado, ya existente, de los Dos Caminos. Para ello emplea y cita las palabras del Señor, según las cuales el cristiano debe orar por su enemigo y exigen la condescendencia con el adversario. De esta manera, el candidato al bautismo recuerda los rasgos característicos de la vida y la doctrina cristiana. El logion adjunto a las limosnas ${ }^{21}$ rememora otra característica de la nueva comunidad a la que accede el neófito: es distintivo de los primeros cristianos incrementar, en la medida de lo posible, el deber judío de cuidar de los pobres. No obstante, el didajista es consciente y tiene la experiencia de que gente sin escrúpulos puede aprovecharse y abusar del sistema de la caridad cristiana, y para evitarlo introduce el dicho: "Que tu limosna sude en tus manos, hasta que sepas a quién das" (v.6) ${ }^{22}$. El texto referido al ayuno dice así:

"Mas la doctrina de estas palabras es como sigue: bendecid a los que os maldicen y rogad por vuestros enemigos y aun ayunad por los que os persiguen. ¿Pues qué gracia tiene que améis a los que os aman? ¿No hacen también eso mismo los gentiles? Mas vosotros amad a los que os aborrecen y no tendréis enemigo" (Did 1,3).

La sección inicia con el mandamiento del amor a los enemigos, aunque no se mencione expresamente que sean palabras del Señor, y su contenido

${ }^{21}$ Did 1,5: "A todo el que te pida, dale y no se lo reclames, pues el Padre quiere que a todos se dé de sus propios dones. Bienaventurado el que, conforme al mandamiento, diere, pues es inocente".

${ }^{22}$ Thomas O'Loughlin, "The Didache as a Source for Picturing the Earliest Christian Communities: The Case of the Practice of Fasting”, en: Kieran J. O'Mahony (ed.), Christian Origins. Worship, Belief and Society. The Milltown Institute and the Irish Biblical Association Millennium Conference (JSNT 241), Sheffield Academic Press, London - New York 2003, 83-112. 
recuerda a la tradición sinóptica (en concreto al logion de la fuente $\mathrm{Q}^{23}, \mathrm{Mt}$ $\left.5,44 / \mathrm{Lc} 6,27 \mathrm{~s} \cdot{ }^{24}\right)$.

\begin{tabular}{|c|c|c|}
\hline Did 1,3 & Mt 5,44.46-47 & Lc $6,27-28$ \\
\hline 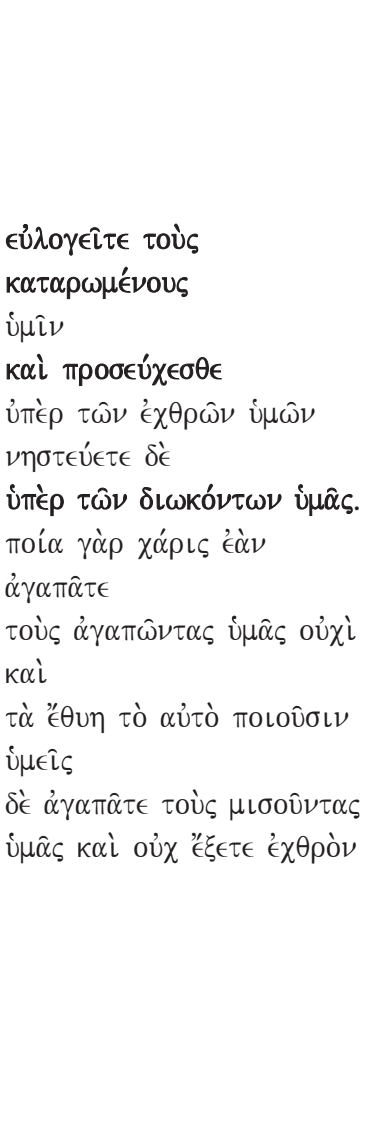 & 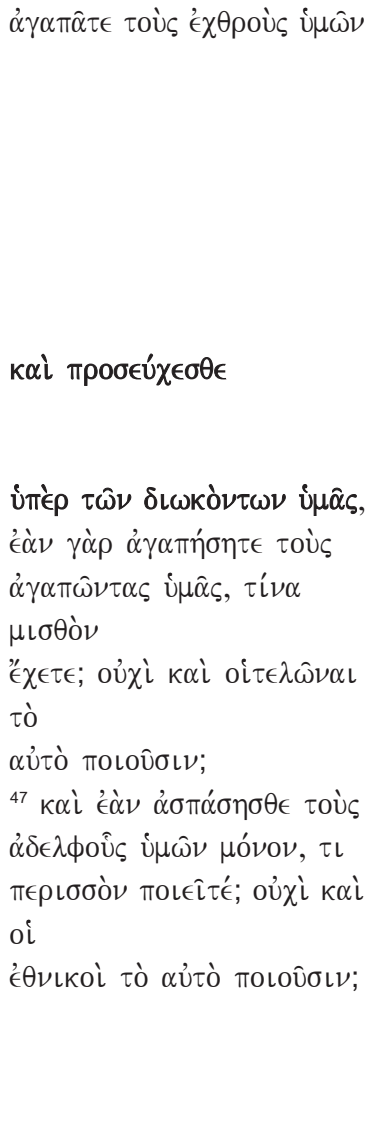 & 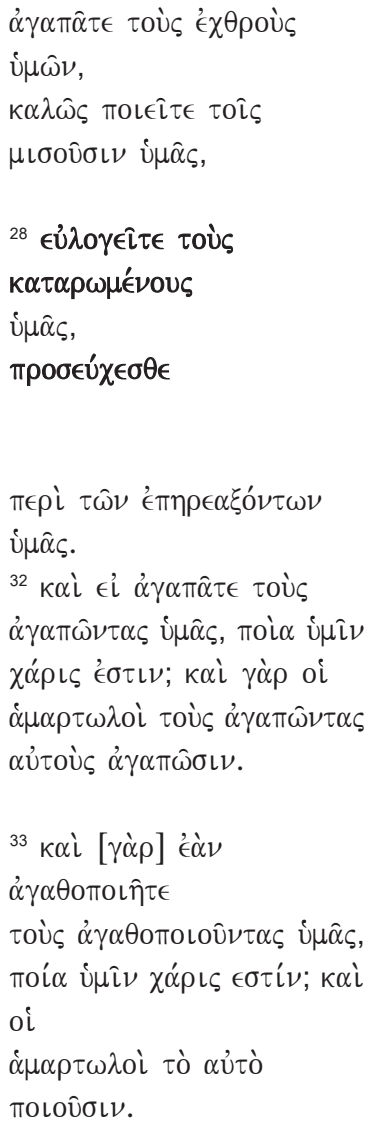 \\
\hline
\end{tabular}

${ }^{23}$ Referente al texto de la fuente Q cf. H.T. Fleddermann, Q. A Reconstruction and Commentary, Peeters, Leuven 2005, 283-294.

${ }^{24}$ Para algunos autores, este paralelismo denotaría una dependencia literaria, por lo que la sección constituiría una interpolación posterior, obra del didajista, cf. las diferentes hipótesis en Kurt Niederwimmer, Die Didache 93-100; Georg Schöllgen, Didache. Zwölf-Apostol-Lehre (Fontes Christiani 1), Herder, Freiburg 2000³, 31: „Umstritten ist jedoch, wann 1,3b2,1 in die Zwei-Wege-Lehre der Didache interpoliert wurden“" Huub van de Sant - David Flusser, The Didache 40-48, deriva de fuentes más recientes: "the section was inserted into Did 1-6 at the time when the earlier Two Ways form was incorporated in the Didache as a whole" (p. 40); Nancy Pardee, The Genre 170-183, atribuye este añadido a la primera etapa 
Una comparación sinóptica de los textos en el recuadro previo nos permite constatar ciertas relaciones, aunque es difícil determinar la precisa naturaleza de las mismas ${ }^{25}$ : diversos rasgos del vocabulario, contenido y orden

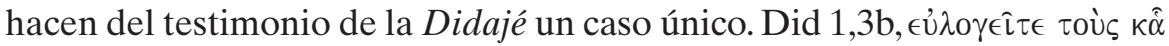

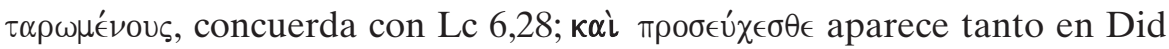

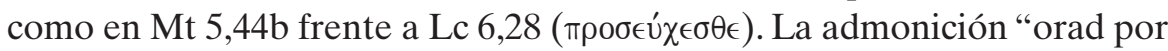
vuestros enemigos" concuerda con Justino, 1 Apol 15,9. La conclusión ủté $\rho$ $\tau \hat{\omega} \nu \delta \iota \omega \kappa o ́ \nu \tau \omega \nu$ í $\mu \hat{\varsigma} \varsigma$ se encuentra en Mt $(5,44)$, pero en Mt se refiere a la expresión $\pi \rho \circ \sigma \in \dot{\chi} \chi \epsilon \sigma \theta \epsilon$, mientras que en la Didajé se emplea con "ayunad"

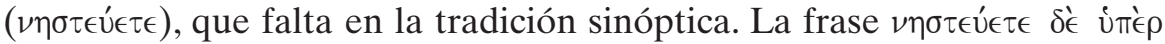
$\tau \hat{\omega} \nu \mathfrak{\epsilon}_{\chi} \theta \rho \hat{\omega} \nu$ i $\mu \omega \hat{s}$ no se encuentra en Mt/Lc, por lo que podría ser un añadido más tardío ${ }^{26}$, procedente bien de la tradición oral paralela (sin ninguna conexión literaria) o (quizás mejor) dependiente de una colección de logia apócrifos o material propio de la Didajé27.

de las cuatro que postula de la cristianización del documento (p. 184). Bentley Layton, "The Sources, Date and Transmission of Didache 1.3b-2.1", HTR 61 (1968) 343-383 y K. Niederwimmer tienen razón al afirmar que hasta el día de hoy no se ha encontrado una solución convincente para esta cuestión. Por su parte, Perttu Nikander, "The Sectio Evangelica (Didache 1.3b-2.1) and Performance", en: Clayton N. Jefford (eds.), The Didache. A Missing Piece, 287-310, argumenta que la sectio evangélica debe su origen a las interpretaciones orales de la tradición de los Dos Caminos y a la interacción constante de los modos de comunicación orales y escritos.

${ }^{25}$ Cf. Huub van de Sandt - David Flusser, The Didache 42s. "The evangelical section, though showing a manifest likeness to certain parts of the Sermon on the Mount, is sufficiently different so as to demonstrate that the composer depended on traditions similar to those used by Matthew and Luke (and Justin), rather than on Matthew, Luke, or Justin themselves. These sources, though their exact form may have varied from place to place, are likely to have circulated in the first century CE in both oral and written forms" (p. 43). "The unit in Did 1:3b-4, [...], probably goes back to a block of saying close to Synoptic tradition but circulating separately" (p. 48). Cf. Willy Rordord, "Le problème" 146: la enseñanza de Did 1,34 es muy próxima a la tradición sinóptica.

${ }^{26}$ Helmut Koester, Ancient Christian Gospels. Their History and Development, SCM Press, London 1990, 315: "This small collection of sayings of Jesus, composed from various sources, is most likely an interpolation which was made after the middle of the $2 \mathrm{~d}$ century". Bentley Layton, "Sources", 353: "an extra-Synoptic addition by the compositor of the Didache passage". Así también Willy Rordorf, "Le probléme de la transmission textuelle de Didachè 1,3b-2,1", en: Willy Rordorf, Liturgie, foi et vie des premiers chrétiens. Études patristiques, Novelle édition reveue et corrigée, Beauchesne, Paris 1986,141s (redactor). No se puede descartar que el pasaje sea redaccional.

${ }^{27} \mathrm{El}$ ayuno por los perseguidores es una adición a la tradición sinóptica existente. El ayuno y la oración a menudo aparecen conjuntamente en los primeros textos cristianos. El 
Al margen del origen de la prescripción del ayuno por los enemigos, la disposición de la frase de la Didajé se encuentra in crescendo respecto a la fuente Q, donde se prescribe el amor y de ahí surgirán los otros mandatos. En nuestro texto, sin embargo, se inicia en primer lugar hablando bien de quienes les maldicen, prosigue con la oración por los enemigos; la siguiente etapa sería ayunar por los enemigos y culmina con el amor a quienes les odian. Se trata pues de actitudes progresivas que tienen que desembocar en el acto supremo de perdón, que es el amor. En este proceso, el ayuno parece reforzar la oración ${ }^{28}$. Probablemente se refiera a un ayuno privado especial, que tiene un carácter intercesor similar a la oración ${ }^{29}$.

Estamos acostumbrados a la troika de la limosna, la oración y el ayuno (cf. Mt 6,2.5.16), pero aquí tenemos bendiciones, oraciones y ayunos. Estas son las tres acciones rituales con las que los cristianos responden a los adversarios. "Ama a tus enemigos y reza por aquellos que te persiguen" (Mt $5,44)$, posiblemente es menos exigente que ayunar por ellos. Aunque es tradicional que uno pueda orar "por" alguien, sin embargo la Didajé va más allá, al defender la concepción de que los beneficios del ayuno puedan ser transferidos a otra persona. Parece que la aceptación de un régimen penitencial puede convertirse en un acto de amor en respuesta a una ofensa. Ello supone un universo espiritual de solidaridad humana ante Dios más parecido a lo que la teología latina más tardía llamaría la transferencia del mérito, y no tan en consonancia con el rechazo a la violencia mediante el acto de poner la otra mejilla (cf. Mt 5,39; Lc 6,29).

ayuno por los perseguidores es raro en las fuentes; cf. J. Schümmer, Die altchristliche Fastenpraxis. Mit besonderer Berücksichtigung der Schriften Tertullians (LQF 27), Münster 1933,222s.; Willy Rordorf, "Transmission" 142: "Did 1,3b hace alusión al ayuno hebdomadario de los miércoles y los viernes (prescrito en Did 8,1), que es realizado por los judíos y no por los gentiles".

${ }^{28}$ Policarpo, A los Filipenses 7,2: "Volvámonos a la palabra que nos fue transmitida desde el principio, viviendo sobriamente para entregarnos a nuestras oraciones, siendo constantes en los ayunos"; Hechos de Tomas 20: "Creemos que es un mago. Pero sus obras de caridad y las curaciones que realiza gratis, su sencillez y amabilidad y la caridad de su fe lo señalan como un hombre justo, o como apóstol del nuevo dios al que predica. Pues ayuna y reza continuamente, come tan solo pan con sal, y su bebida es agua. Lleva un único vestido tanto en buen tiempo como cuando hace frío”; 145: “No sean vanos mis esfuerzos! ¡No se pierdan mis plegarias y mis continuos ayunos, ni queden disminuidas mis obras por ti!".

${ }^{29}$ Cf. 2 Sam 12,15-23; Ester 4,16. 


\section{Ayuno y los ritos de pasaje $\mathrm{e}^{30}$}

Una segunda mención del ayuno se encuentra al final de las instrucciones sobre el bautismo. Al autor o redactor no le preocupa la organización integral del rito del bautismo, sino simplemente la regulación autoritativa de algunos temas controvertidos, como es el tipo de agua bautismal, el ayuno previo o la fórmula ritual empleada. Tras abordar la cuestión de la forma y la materia bautismal, señala la preparación inmediata para el mismo: "Antes del bautismo, ayunen el bautizante y el bautizando y algunos otros que puedan. Al bautizando, empero, le mandarás ayunar uno o dos días antes" (Did 7,4). Este versículo representa el testimonio más antiguo del ayuno prebautismal, pues en ningún lugar del NT se encuentra dicho mandato, aunque Hechos insinúa la existencia de algún tipo de ayuno semejante ${ }^{31}$. Tal y como sugirió J. Schümmer, la costumbre del ayuno prebautismal es posiblemente incluso más antigua que el ayuno general de Pascua $^{32}$ y pudo contribuir a convertir el ayuno de Pascua en una praxis general ${ }^{33}$.

Estas exigencias se encuentran recogidas de forma semejante en otras fuentes antiguas cristianas ${ }^{34}$, tanto para el bautizando $\mathrm{o}^{35}$, como para el agente

${ }^{30}$ Para una argumentación elaborada referente a los días de ayuno y el bautismo en base a Did 7,4 y 8,1, cfr., F.R. Prostmeier, "Unterscheidenes Handeln. Fasten und Taufen gemäss Did 7,4 und 8,1", en: Johannes Baptism Bauer (ed.), Philophronesis: für Norbert Brox (GTS 19), Institution für Ökumen. Theologie und Patrologie, Graz 1995, 55-75.

${ }^{31}$ No se duda de que un ayuno prebautismal constituyó una praxis antigua dentro de algunas comunidades, tal y como lo confirma indirectamente Lucas en Hch 9 cuando presenta el ayuno que tiene lugar antes del bautismo de Pablo. Cf. F.R. Prostmeier, "Unterscheidenes Handeln" 58.

${ }^{32}$ La Didascalia habla del ayuno pascual en el capítulo XXII dedicado a la Pascua y resurrección de Cristo:XIV 15-17: ¿¿Por qué ayunáis estos días por mi causa?... Lo habéis hecho por vuestros hermanos; y lo haréis en estos días en que habéis ayunado: el miércoles y el viernes, siempre, como está escrito en Zacarías (Za 8,19) acerca del ayuno del día cuarto y del ayuno del día quinto, que es el viernes. Pero no os está permitido ayunar en domingo, porque es el día de mi resurrección. Por eso, el domingo no cuenta en el número de los días de ayuno de la pasión, sino que empiezan a contar a partir del lunes y hay cinco días. Por tanto, el ayuno del día cuarto, así como el del día quinto, el del séptimo y el del décimo serán para la casa de Israel. Vosotros ayunaréis, pues, a partir del lunes, seis días completamente, hasta la noche que sigue al sábado, y (esto) os será contado (por) una semana”. Cf. XIV 23 (ayuno de los días de Pascua); XX 9.

${ }^{33}$ Die altchristliche Fastenpraxis, 169.

${ }^{34}$ Niederwimmer, Die Didache 164; Wengst, Didache (Apoltellehre) 97, n 62; RordorfTuilier, La Doctrine des douze Apôtres 172, n. 3.

${ }^{35}$ Hipólito, Trad. Apost 20 (sahid.) (SC 11,78): "Quienes reciben el bautismo, ayunen el viernes y se reúnan en el mismo lugar según determine el obispo"; Tertuliano, de bapt 20,1. 
ritual $^{36}$. Ya en el año 150 d.C., Justino menciona un ayuno preparatorio para el bautismo:

"Cuando se convencen y tienen fe de que son verdaderas estas cosas que nosotros enseñamos y decimos y prometen poder vivir conforme a ellas, se les instruye ante todo para que oren y pidan, con ayunos, perdón a Dios de sus pecados anteriormente cometidos, y nosotros oramos y ayunamos juntamente con ellos. Luego los conducimos a un sitio donde hay agua, y por el mismo modo de regeneración con que nosotros fuimos también regenerados, son regenerados ellos" (1 Apología 61,2-3a).

A la hora de examinar este breve capítulo dedicado al bautismo en la Didajé, los comentarios consideran que 7,1b es un elemento redaccional para referirse a la sección previa de los Dos Caminos. Igualmente, los versículos 7,2-3 y 4b serían un añadido posterior, dirigido expresamente a quien administra el bautismo, como pudiera reflejar el cambio de persona $\left(2^{\mathrm{a}} \mathrm{sin}\right.$ gular $\left.^{37}\right)$. El texto originario se reduciría a 7,1c $+4 a$, es decir, a la indicación de bautizar con la fórmula trinitaria en agua corriente y hacer preceder el bautismo de un ayuno, al que el redactor habría añadido la casuística relativa al tipo de agua (2-3) y la indicación sobre el periodo temporal del ayuno del bautizando ${ }^{38}$. Otros autores, por el contrario, consideran el carácter unitario de la sección, aunque haya sido compuesta gracias a materiales tradicionales $^{39}$, para lo cual aducen que si la indicación temporal del ayuno del bautizando fuera una codificación más tardía, entonces se esperaría que fuera más precisa, mientras que aquí refleja cierta indeterminación ("uno o dos días") y se correlaciona con la discrecionalidad del ayuno de los miembros de la comunidad ("si pueden"). Según K. Niederwimmer, el $d i$ -

Constituciones Apostólicas VII 22,4-5: "Que ayune quien va a ser bautizado antes del bautismo, pues también el Señor fue bautizado antes por Juan... Fue bautizado y ayunó, no porque necesitara una ablución o un ayuno... sino para que diera testimonio de la verdad a Juan y nos proporcionara un ejemplo".

${ }^{36} \mathrm{El}$ ayuno del agente ritual y de otras personas antes del bautismo se encuentra (implícito) en Ps. Clem, hom XIII 12,1; (explícito) recogn. VII 37,1 (GCS 51, 214).

${ }^{37}$ En contra se muestra Aaron Milavec, Didache 244-246.

${ }^{38}$ Sobre el aspecto de la unidad literaria de Didajé 7, cf. ampliamente, Willy Rordorf, "Baptism according to the Didache", en: Jonathan A. Draper (ed.), The Didache in Modern Research, 213-215. Sobre el bautismo en la Didajé cf. A. Vööbus, Liturgical Traditions in the Didache, Stonian Theological Society in Exile, Stockholm 1968, 17-39.

${ }^{39}$ Giuseppe Visonà, Didachè. Insegnamento degli apostoli, Paoline, Milano 2000,135s. 
dajista recogió en el cap. 7 un documento previo (Vorlage) judeocristiano rigorista, lo liberalizó mediante añadidos y lo adaptó a sus circunstancias ${ }^{40}$.

\subsection{Los sujetos del ayuno}

El primer hemistiquio del versículo 7,4 determina que tanto el agente ritual como el candidato al bautismo deben ayunar antes del bautismo. Sorprende que el primer interpelado en ayunar sea el agente ritual en lugar del candidato. Para A. Milavec sería una forma de enseñar con el ejemplo lo que significa ayunar y el impacto que el ayuno tenía en la vida del seguidor de Jesús ${ }^{41}$. Asimismo, se invita a ayunar también a "otros" que estén

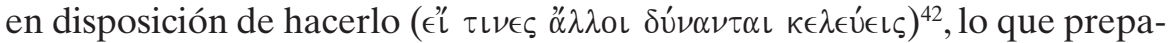
raría sus corazones y mentes para recibir a nuevos miembros dentro del grupo y concluiría en la fiesta de acogida (eucaristía). El segundo hemistiquio del versículo establece para el bautizando el período de uno o dos días de ayuno antes del bautismo ${ }^{43}$, sin embargo no se señala ninguna indicación temporal de la duración del ayuno para el agente ritual, ni para otros miembros de la comunidad que deseen participar en él, ni tampoco la rigurosidad del mismo. El enfático $\kappa \in \lambda \in \dot{\epsilon} \in \iota \zeta$ deja claro que el ayuno prebautismal tiene un mayor grado de compromiso para el bautizando que para el resto de los participantes.

La indeterminación de invitar a "otras" personas de la comunidad a unirse en el ayuno, hizo que Michel Dujarier ${ }^{44}$ pensara en una etapa preli-

${ }^{40}$ Según Kurt Niederwimmer, Die Didache, 159.164, Did 7,4a constituiría una antigua tradición, mientras que la segunda frase $(7,4 \mathrm{~b})$ sería redaccional.

${ }^{41}$ Aaron Milavec, Didache 243.258. Además durante este tiempo de ayuno, el mentor podía orientar a los novicios sobre el ayuno bisemanal.

${ }_{42}$ Aaron Milavec, Didache 258, da a entender que la Didajé exige en esta expresión ampliar su ayuno un día más, aunque dos días continuos constituye un ayuno de rigor inusual.

${ }^{43}$ Uno o dos días es probablemente también el tiempo de ayuno prebautismal en Hipólito, Trad. Apost. 20. Un ayuno bautismal viene prescrito en Ps. Clem, hom XIII 11,4; sobre la cuestión del ayuno un día antes del bautismo véase hom XIII 9,3; recogn VII 34,3; hom. XIII 10,7; recogn VII 35,7; hom XIII 12,1. Sin embargo, las Pseudoclementinas conocen el ayuno prebautismal de varios días ( $h o m$ III 73,1); un ayuno de tres meses antes del bautismo (hom XI 35,1; recogn III 67,1ss). Estas diferencias de la duración del ayuno se explican por las diversas formas más rigoristas de ayunar.

${ }^{44}$ Le parrainage des adultes aux trois premiers siècles de l'Église (Parole et Mission 4), Ed. du Cerf, Paris 1962, 292-297. 
minar de la institución posterior del padrinaje o en el inicio de la práctica del patrocinio por parte de los padrinos. Se trataría, por consiguiente, de personas especialmente allegadas al candidato durante el período de preparación bautismal y que, tal vez, incluso lo avalaran ante la comunidad. Willy Rordorf considera esta propuesta hipotética. No obstante, “creo que tiene razón al decir que uno debe considerar la participación de varias personas en el ayuno como una realidad y no como una posibilidad" ${ }^{45}$. Es cierto que son miembros de la comunidad; sin embargo, el texto no señala ningún tipo de vinculación particular a la persona bautizada, sino que enfatiza la disposición personal. El ayuno de algunos miembros de la comunidad viene asimismo testimoniado por Justino, aunque según algún estudioso pudiera haber desaparecido pronto: Llama la atención que el v. 4b haga referencia solo a los días de ayuno del bautizando, por lo que podría ser un añadido del redactor y que en su tiempo solo ayunara el bautizando ${ }^{46}$.

\subsection{El día o días del ayuno prebautismal}

¿Existía algún día estipulado de la semana para el ayuno prebautismal? Lógicamente, si supiéramos que el bautismo se celebraba en una fecha precisa de la semana, entonces se podría establecer el día del ayuno. Sin embargo, la Didajé no especifica el momento preciso del día, ni el día de la semana, ni el tiempo litúrgico para realizar el bautismo, ni hace ningún intento por coordinar el ayuno prebautismal con el ayuno comunitario que propondrá en el capítulo siguiente, los miércoles y viernes (Did 8,1) ${ }^{47}$. Ante dicho silencio, se ha conjeturado que tal vez el bautismo fuera administrado en domingo, pues Did 14 conoce el domingo como día de culto cristiano ${ }^{48}$.

${ }^{45}$ Willy Rordorf, "Baptism” $216 \mathrm{~s}$.

${ }^{46}$ Niederwimmer, Die Didache 164, piensa que "en tiempo de la redacción, ayuna solo el bautizando"; William Varner, The Way of the Didache. The First Christian Handbook, University Press of America, Lanham 2007, 74 expresa una idea semejante: "The fasting of the baptizer probably soon went out of use"; Huub van de Sandt - David Flusser, The Didache 279, n. 22.

${ }^{47}$ Ampliamente al respecto F.R. Prostmeier, "Unterscheidenes Handeln" 66ss., quien concluye: "Für das zweitägige Katechumenatsfasten bleiben also nur Dienstag und Mittwoch oder Freitag (Rüsttag) und Samstag (Sabbat)" (p. 67).

${ }^{48}$ Willy Rordorf, Sabbat und Sonntag in der Alten Kirche (Tradition Christiana 2), Theologischer Verlag, Zürich 1972, 139, n. 5: „Kap. 65 steht in so enger Parallele zu Kap. 67, dass man mit Recht vermuten darf, auch die Taufe sei am Sonntag gespendet worden, wenn Taufbewerber vorhanden waren". 
Además, según Justino, la iglesia romana de mediados del siglo II celebraba el bautismo de los candidatos solo los domingos por la mañana, antes de la eucaristía semanal ${ }^{49}$. Plinio también habla de la reunión litúrgica de los cristianos en ese mismo día de la semana.

De esta opinión es van de Sandt ${ }^{50}$, quien defiende que el bautismo se realizaba el domingo y los días de ayuno prebautismales coincidirían probablemente con los días de ayuno oficial comunitario impuestos en Did 8,1. Cuando un candidato al bautismo realizaba un ayuno privado por un período de dos días, solo los martes/miércoles o los viernes/sábados eran elegibles. En este último caso, las fechas en cuestión eran el día de preparación para el sábado y el mismo sábado. Relevante para nuestra discusión referente al día más propicio para el bautismo en la comunidad de la Didajé es

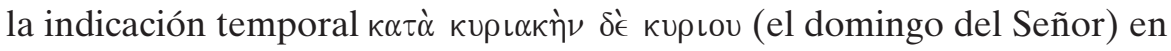
Did 14,1, por lo que el domingo constituía el día de la celebración de la eucaristía, precedida, en caso de que hubiera candidatos a adherirse a la comunidad cristiana, del bautismo. El ayuno de uno o dos días antes de la ceremonia del bautismo implicaría en cierto sentido una cierta violación del sábado ${ }^{51}$, pues las sectas judías más estrictas se negaban a ayunar durante ese día festivo de la semana ${ }^{52}$. El séptimo día era el día de descanso

${ }^{49}$ Justino informa que el bautismo estaba precedido por un ayuno comunitario "para la remisión de los pecados" (1 Apol 41 (¿61?), sin que se mencione la duración del mismo.

${ }^{50}$ Huub van de Sandt, "The Didache Redefining", 263. F.R. Prostmeier, "Unterscheidenes Handeln" 69: "Aus organisatorischen sowie pastoralen Gründen, und weniger aus theologischen Erwägungen, wird dann die Wahl auf den Herrentag, und nicht auf einen anderen terminlich möglichen Wochen- oder Jahrestag gefallen sein”.

${ }^{51}$ Era un deber disfrutar el sábado con una buena comida (Neh 8,10; Tob 2,1). No se permitía el ayuno en sábado porque era un día festivo (Jub 50,10.12) y, según Jud 8,6 esta prohibición también se aplica al día que lo precede. En b.Taan 17b (= b.RH 19a), la regla prohibitoria se expresa de la siguiente manera: "En sábados y días santos, está prohibido [ayunar]; en [los días] anteriores y posteriores a ellos, está permitido".

${ }^{52}$ Por el contrario, Margaret Williams, "Being a Jew in Rome: Sabbath Fasting as an Expression of Romano-Jewish Identity”, en: John M.G. Barclay (ed.), Negotiating Diaspora. Jewish Strategies in the Roman Empire (LSTS 45), T \& T Clark, London - New York 2004, 8-18, aduce cómo diversos autores romanos de finales del siglo I hasta mediados del s. II d.C. conocen la tradición de que judíos romanos ayunan en sábado como una praxis local y rasgo distintivo de identidad, constatando que estos autores se sorprenden de que los judíos celebren un día tal especial para ellos mediante el ayuno. Según la opinión de Heather A. McKay, Sabbath and Sinagogue. The Question if Sabbath Worship in Ancient Judaism, EJ. Brill, Leiden - New York - Köln 1994, 91-131, esta confusión acerca del sábado y el ayuno en autores 
judío, en el que estaba prohibido pasar sin comer hasta el mediodía ${ }^{53}$. La única jornada fija de ayuno que se celebraba en sábado era el día de Yom Kippur. El resto de los días de ayuno, si coincidían con el sábado, eran pospuestos o adelantados un día. Por lo tanto, van de Sandt concluye que la comunidad de la Didajé había abandonado, al menos parcialmente, la observancia del sábado judío. Si ese es el caso, la instrucción en Did 7,4 pudiera reflejar una cierta ruptura de la comunidad de la Didajé de sus raíces judías.

Sin embargo, Aaron Milavec ${ }^{54}$ considera que en circunstancias normales, la comunidad habría preferido que la comida que rompía el ayuno, fuera el ágape eucarístico. Si la eucaristía semanal se celebraba en el día del Señor $(14,1)$, siguiendo el cálculo judío del final del sábado $(8,1)$, entonces se podría esperar que el bautismo se realizara preferentemente el sábado por la noche, justo antes de la eucaristía semanal. Dicha disposición también tendría la ventaja de garantizar que la mayoría de los miembros de la comunidad pudiera participar en el rito bautismal tras la jornada laboral. Según este autor, las comunidades de la Didajé celebraban su eucaristía semanal en la noche del sábado. Es más plausible que la vinculación de bautismo - eucaristía tuviera lugar al final del día laboral, pues los bautismos al final de la tarde en un río o una piscina podían tener un aspecto refrescante tras el calor sofocante del día, además de que la asamblea, reunida para acoger al nuevo bautizado en su nueva "familia", tenía el deseo de romper su ayuno y celebrar juntos la fiesta eucarística.

Si esas mismas prácticas aparecen en la iglesia de Roma a mediados del siglo II celebrándose al alba dominical ${ }^{55}$, se debió según Aaron Milavec por

latinos pudo haber surgido a causa de los escritos de Josefo, especialmente del pasaje Apión 2,282-83. "This passage, whether by chance or on purpose, definitely links Sabbath, rest, fasting, the lighting of lamps and food rules-though, as far as we know, there was no requirement to fast on the Sabbath" (p. 96).

53 'Está prohibido ayunar hasta la hora sexta del sábado' en p.Taan 3,67a (= p.Ned 8, 40d). La misma ley es mencionada por Josefo en su Vida 54: "[Y un disturbio habría ocurrido inevitablemente], no hubiera llegado la sexta hora, en la cual es nuestra costumbre el sábado tomar nuestra comida del mediodía [interrumpida la reunión]".

${ }^{54}$ Aaron Milavec, The Didache 238. "The first day of fasting would have been the semiweekly fast on 'the Sabbath preparition day' (8:1) and the second day of fasting would have fallen on the Sabbath day itself" (p. 258).

${ }^{55}$ D.E. Aune, "Worship, Early Christian", $A B D$ VI 973-989, refiriéndose a los días de culto, considera que el momento de la reunión es ciertamente el domingo por la noche en lugar del sábado por la noche, aunque esta cuestión depende de si uno utiliza el modo judío 
otros motivos externos, como pudo ser la imposición del toque de queda prohibiendo a todos los grupos reunirse después de la puesta del sol ${ }^{56}$. Es difícil imaginar que el domingo por la mañana se convirtiera en la elección preferida y voluntaria de la comunidad para celebrar el bautismo en la hora más fría y oscura del día y que el aspecto festivo de las cenas comunitarias relajadas y ociosas tuviera que rendirse a favor de las eucaristías de "desayuno". Durante el resto de las horas diurnas del domingo, los cristianos, como el resto de los habitantes del Imperio Romano, tenían que trabajar.

\subsection{Motivación del ayuno}

La gran dificultad de este texto (Did 7,4) acerca del ayuno prebautismal radica en que, si bien establece una regla sobre quién debe ayunar y durante cuánto tiempo, sin embargo no aduce ningún motivo para el mismo, ni ofrece indicios de cómo se percibió el propósito de esta praxis, ni teorías sobre el origen o sus beneficios ${ }^{57}$. Esto hace pensar que la praxis del ayuno antes del bautismo no fue una creación de la Didajé, sino que simplemente está dando voz a una tradición ya practicada. Es posible que el período de ayuno de uno o dos días sirviera para producir en un converso gentil un sentido de separación del mundo pagano, ya que el ayuno implicaba el arrepentimiento y la remisión de los pecados, así como la ruptura de compartir los alimentos sacrificados a los ídolos $(6,2)$, constituyendo el bautismo un rito de pasaje y el ayuno el elemento liminal de este rito ${ }^{58}$. Esta praxis del ayuno pudo servir para intensificar el sentimiento de dolor por la ruptura con el mundo pasado.

Según algunos comentaristas, este ayuno dispondría al receptor para recibir una iluminación divina; sin embargo, eso no explicaría la necesidad

de computar el tiempo (de la puesta del sol a la puesta del sol) o el romano (del amanecer al amanecer). El momento de la reunión parece haber sido el domingo por la noche hasta principios del siglo II, cuando por varias razones el servicio principal de culto se trasladó desde el domingo por la noche al domingo por la mañana, antes del amanecer (p. 979).

${ }^{56}$ Aaron Milavec, The Didache 240.

${ }^{57}$ Cf. Schümmer, Lent Practice 174-178. De entre los diversos motivos se pueden mencionar el apoyo a la oración, expiación por los pecados, la expulsión de los demonios del cuerpo del candidato bautismal.

${ }^{58}$ Aaron Milavec, Didache 244. Para los tres estadios de un ritual de transformación de estatus en la Didajé (separación - liminalidad - agregación) cf. Richard S. Ascough, "An Analysis of the Baptismal Ritual of the Didache”, Studia Liturgica 24 (1994) 201-213. 
de que el ministro ayune, ni sabemos si entendieron el bautismo en términos de iluminación. Más bien, si el bautismo era un momento decisivo tanto para el individuo como para la comunidad, el ayuno se consideró parte de la preparación para un evento religioso importante, de manera que todos los involucrados tenían que estar espiritualmente preparados. Como modelo e inspiración se podía aducir el ayuno de Moisés durante 40 días antes de recibir la Ley (Éx 34,28) o Daniel esperando una revelación (Dan 10,3). Es probable que, en el contexto de su propio ayuno prebautismal, entendieran de esta forma las tradiciones sobre el ayuno de Jesús antes de su ministerio público (Mc 1,13; Mt 4,2 y Lc 4,2) ${ }^{59}$. También es posible que el ayuno previo al bautismo fuera penitencial, para el que existía un precedente en 1 Sam 7,6, por lo cual constituiría una purificación del candidato antes de entrar a formar parte de los elegidos de Cristo. Si se acepta la idea de que imaginaron un universo donde los beneficios espirituales podían transferirse de una persona a otra, entonces el ayuno de diversos miembros de la iglesia produciría un beneficio transferible al nuevo miembro para que el iniciado se alejara de sus pecados y accediera a Cristo.

Una explicación más elaborada, siguiendo el escenario que se acaba de proponer, relacionaría este ayuno con una conexión que hace la comunidad entre el bautismo y el exorcismo, que luego se convertiría en parte integrante de los ritos bautismales. Vööbus abordó esta posibilidad: Se creía, en base a evidencias posteriores, que el ayuno tenía un poder purificador y expiatorio. También se sostuvo que el ayuno podía aniquilar el poder de los demonios y fortalecer la eficacia de la oración del candidato. De esta forma se prepararía el candidato para la recepción del Espíritu Santo ${ }^{60}$.

Si el ayuno fuera solo del candidato, entonces el ayuno como preparación espiritual pudiera proporcionar una explicación, pero la participación del ministro y de otros miembros de la comunidad indica que el ayuno es un acto colectivo de intercesión por el candidato. Todos los involucrados deben trabajar conjuntamente para lograr la expulsión de los espíritus del individuo. Si se sigue esta línea de argumentación, entonces nuevamente tenemos la noción de que el efecto del ayuno debe entenderse en términos de solida-

${ }^{59}$ Dado que el ayuno antes y después del bautismo implicaba arrepentimiento y remisión de los pecados previos, estas características podrían haber derivado de alguna forma del bautismo de Juan, y la Didajé mostraría un estadio en el desarrollo de este ritual, cf. Huub van de Sandt - David Flusser, The Didache 280.

${ }^{60}$ A. Vööbus, Liturgical Traditions in the Didache, Stonian Theological Society in Exile, Stockholm 1968, 20. 
ridad espiritual de toda la comunidad: participar juntos en este acto colabora en la santidad de la iglesia. No solo el candidato debe enfrentarse al demonio, sino también el ministro que lleva a cabo el exorcismo y que, por tanto, necesita ser fortificado para la confrontación, y con ellos colaboran todos los demás miembros de la comunidad que han optado por ayunar.

En apoyo de la posibilidad de que entendieran el ayuno como parte de un ritual de exorcismo, solo tenemos una evidencia tentadora: Según Mc 9,29 existen demonios que "solo pueden ser expulsados mediante la oración y el ayuno". Al igual que en la Didajé, existe la suposición de que para la salud espiritual del individuo se requiere la acción generosa y físicamente exigente de toda la comunidad.

Cuando Lucas relata la elección de Bernabé y Saulo por parte de la iglesia en Antioquía (Hch 13,2-3), el nombramiento de Pablo de presbyteroi en las iglesias donde él había predicado (Hch 14,23) tiene lugar después de un ritual preparatorio de oración y ayuno. Lc asume que los momentos significativos de la vida de cada comunidad se acompañan de un período especial de ayuno y oración, y que esta práctica se remonta a las comunidades más antiguas. Hch 9 apunta a un ayuno antes del bautismo por parte del que espera el bautismo, mientras que Hch 13 y 14 asumen un ayuno más general de la comunidad para prepararse para un evento eclesial central; juntos indican que el ayuno era una práctica importante en las comunidades de Lc, incluso si algunos de los detalles de su regulación eran diferentes a los encontrados en la comunidad de la Didajé. Además, dado que la Didajé es anterior, muestra que Lc tenía razón al suponer que la práctica era primitiva. En los tres casos, la acción del ayuno se presenta como parte integral de una liturgia compleja. Hch 9 ofrece una abstinencia de alimentos, que inicia con una visión y concluye con un ritual. Hch 13 asume que una vez que la elección de quienes debían enviarse se había hecho bajo la inspiración del Espíritu Santo, ahora era necesario proceder con el ritual apropiado que implicaba la secuencia de:(1) oración y ayuno; (2) imposición de manos; y (3) envío. En Hch 14, 'oración y ayuno' es una parte específica del ritual para designar presbyteroi. En la Didajé existe el período de oración y ayuno, seguido del bautismo. Sin embargo, estos documentos no ofrecen una justificación de por qué el ayuno formaba parte de estos ritos de paso.

El significado que las comunidades originarias otorgaron a este ayuno bautismal sigue siendo una cuestión de conjeturas ${ }^{61}$ y las explicaciones que

${ }^{61}$ Aaron Milavec, Didache 253-255, propone seis posibles significados: a) ayuno como intensificación de la oración, b) como intensificación de la conversión: el ayuno y la oración 
se proponen, constituyen una justificación post factum en lugar de una explicación del hecho: fue su práctica la que sobrevivió en las comunidades, no su significado. De tal forma que el ayuno pre-bautismal se convirtió en un elemento fijo en los últimos días del catecumenado. Se menciona en Justino (Apol 1.61); Tertuliano (De bapt. 20) e Hipólito (Trad apost. 20) comentan ese ayuno; y, más tarde aún, Agustín en varias ocasiones (por ejemplo, De fide 6,8 y Epist 54,10) analiza su importancia.

Las diferencias en la práctica del bautismo, un rito que era de gran importancia para la iglesia primitiva, podrían causar tensión entre las comunidades cristianas. A través de la regulación de estas prácticas, la Didajé pretende unificar la praxis de sus comunidades y, así, mejorar su cohesión. Además, varios elementos de la instrucción, como la fórmula trinitaria y el ayuno pre-bautismal, reflejan una cierta separación de la comunidad cristiana frente a otros grupos judíos. Esto hace que sea más importante remodelar la identidad cristiana del grupo.

\section{Conclusión}

La pluralidad de grupos cristianos en las primeras décadas muestra diversas actitudes hacia algunos rituales del judaísmo. Esto mismo se constata en la praxis del ayuno. Aunque no jugó un papel relevante en la predicación del Jesús histórico, ni en Pablo, ni en otros grupos de seguidores posteriores de Jesús, sin embargo otros círculos cristianos vinculados a sus raíces judías, asumieron y adaptaron la praxis del ayuno, e incluso la imponen como obligatoria. La Didajé es un caso llamativo pues otorga a este ritual un significado novedoso, lo que denota que esas comunidades fueron creativas a la hora de adoptar la herencia judía desde muy antiguo.

Si aceptamos la datación temprana de este opúsculo (década de los 70 d.C.), los textos analizados corroboran que los ritos constituyeron la primera expresión y la más compartida del grupo sin necesidad de un componente doctrinal. Este aparecerá con el tiempo para intentar justificar esos

pueden ayudar a enfrentarse a todos los retos que exige la conversión a una nueva forma de vida, c) como respuesta natural a un evento transcendental, d) ayuda ante la pérdida traumática de identidad debido a la situación liminal del converso en este rito iniciático, e) como sistema de purificación ante los alimentos sacrificados a los ídolos y f) como preparación para el ayuno bisemanal. 
gestos, tal y como se constata en el mandato del ayuno bisemanal de la comunidad de la Didajé $(8,1)$ : prescribe los días de ayuno, pero no lo justifica desde el punto de vista teológico. Habrá que esperar décadas para que autores cristianos aduzcan una explicación o fundamenten teológicamente una praxis que ya se realizaba en esas comunidades.

Las acciones rituales contienen exigencias vitales. En el catecumenado que precedía al bautismo se enseñaba, siguiendo la tradición judía, los comportamientos del discípulo de Jesús. De entre los ritos más generalizados y fundamentales que encontramos en los grupos cristianos de los orígenes se halla el rito de iniciación o incorporación a la comunidad, que es el bautismo. La Didajé señala la preparación inmediata para este rito, mencionando expresamente el ayuno prebautismal del bautizando y del agente ritual, constituyendo así el testimonio más antiguo de esta exigencia. Aunque el opúsculo determina quién debe ayunar y la duración del mismo, sin embargo no explica el motivo del mismo, ni lo intenta justificar. Simplemente transmite una tradición ya practicada, aunque no unánimemente observada por los miembros de su grupo. Este ayuno pretendía ser un elemento liminal por el que el candidato rompía con su mundo gentil, al tiempo que considera esta praxis como un acto colectivo de intercesión por el candidato, por lo que el efecto del ayuno debe entenderse en términos de solidaridad espiritual de toda la comunidad. Esa misma solidaridad se manifiesta cuando se prescribe ayunar por los enemigos, pues los beneficios del ayuno pueden ser transferidos a otra persona. 